\title{
A Language Course Within the Scheme of Socially Responsible Teaching: ELT Trainees' Expectations
}

\author{
Esim Gürsoy
}

Uludağ University esimgursoy@yahoo.com

Pınar Salı

Doi:10.5901/jesr.2014.v14n2p355

Uludağ University pinarsali@yahoo.com

\begin{abstract}
The current study aims at investigating ELT teacher trainees' expectations from a GILE-based course (Global Issues in Language Education) conducted in a large state university in Turkey. The course was offered in the ELT program for the first time as an elective to increase trainees' awareness on global issues while improving their language skills. A quasiexperimental research design was adopted to investigate trainees' expectations from the course. Data were collected via a questionnaire administered before and after the course was implemented to compare the trainees' expectations from and views about the GILE-based course. All of the fourth-year ELT trainees ( $N=28)$ enrolled in the course contributed to the study. The qualitative and quantitative analysis of data indicated that the participants had positive attitudes towards the inclusion of environmental issues in foreign language learning and teaching. However, only a minority of teacher trainees considered GILE as essential for language teacher training. The findings were discussed in relation to foreign language teaching education.
\end{abstract}

Keywords: GILE, SRT, language teacher education, ELT, environmental education

\section{Introduction}

The current study aims at investigating ELT teacher trainees' expectations from a GILE-based course (Global Issues in Language Education) conducted in a large state university in Turkey. The course was offered in the ELT (English Language Teaching) program for the first time as an elective to increase trainees' awareness on global issues while improving their language skills. As part of the critical pedagogy (Freire, 2005), Socially Responsible Teaching (SRT) has been one of the concerns in language education. However, this has not been reflected in most language teacher education programs.

The inclusion of this elective course in the ELT program is an attempt to integrate SRT and GILE into language teacher education and thus to contribute to the linguistic and social development of ELT trainees. Teacher trainees' views on this newly-introduced GILE-based course are prominent as it would contribute to the development of the aforementioned course as well as other similar courses as part of SRT philosophy. This would, in turn, help maintain efforts to make future language teachers socially aware and responsible citizens.

\section{Literature review}

SRT is one of the reflections of Critical Pedagogy, which highlights the need to develop students' critical stance towards their own education and society (Freire, 2005). This, as argued by Critical Pedagogy, would allow students to be active participants in the transformation of their society as socially aware and responsible individuals. According to Freire (2005), education is not a means to transfer information. Rather, it is an act of cognition. He thus strongly opposes the banking model of education where students are the passive recipients of information. Teachers and students are the cognitive actors in a learning situation. Like Dewey, Freire also relates the act of knowing to inquiry (Deans, 1999). Accordingly, inquiry is necessary for men to be truly human. As Freire (2005) states "Knowledge emerges only through invention and re-invention, through the restless, impatient, continuing, hopeful inquiry men pursue in the world, with the world, and with each other" (p. 72). Hence, a view that considers the learners as "empty containers" to be filled by the teachers will do injustice to the process of learning. As Shor and Freire (1987) explain learning involves "action, critical reflection, curiosity, demanding inquiry, uneasiness, uncertainty-all these virtues are indispensable to the cognitive subject, the person who learns!" (p. 8). From this point of view integration of SRT topics to education would help learners 
to think critically on global issues, create opportunities for reflection, trigger curiosity on issues concerning the society and the world, help develop an understanding on these issues and encourage learners to take part in solutions to those problems.

Within the framework of all these, 'Global Education' (GE henceforth) has emerged as an approach which invests efforts in developing 'the knowledge, attitudes and skills relevant to living responsibly in a multicultural, interdependent world' (Fisher and Hicks, 1985, p. 8). GE attempts to bring about this development through a 'change in the content, methods and social context of education in order to better prepare students for citizenship in a global age' (Kniep, 1985, p.15).

The content of GE consists of global issues ranging from environment, development and human rights, to peace and conflict, race, gender, health and education (Hicks and Bord, 2001). These global issues have found their ways into different fields of study such as 'peace education, environmental education, development education, and human rights education' (Peaty, 2004, p.15).

Global issues have also attracted considerable attention in foreign language teaching as the focus of foreign language learning and teaching has shifted from rather structure- based approaches to communication and meaningbased ones (Gürsoy and Sağlam, 2011). This shift has necessitated the presentation and practice of language within meaningful contexts, and the contents of GE have thus constituted one of the frames of reference for the teaching and learning of foreign languages meaningfully. Aside from providing meaningful and natural contexts for the teaching and learning of foreign languages, the use of global issues in foreign language education might aid in the culmination of 'the knowledge, skills and commitment required by world citizens to solve global problems' (Cates, 1990, p.41). As the citizens of the world, global problems are our responsibility. The results of the drastic changes in the world's climate, loss of land, deforestation, poverty, reckless use of energy etc. are some of these problems that have an effect on global community. In one of the most recent reports on the impact of global warming scientists claim that global warming is not just showing its effects on polar bears, but the danger is immediate and local, the results of which will be hunger, disease, drought, flooding, refugees and war (Yahoo News, 2014). Due to these alarming changes on the earth's ecological system and the rapid loss of energy sources, it becomes one of the responsibilities of education to help individuals to develop an understanding and create an awareness regarding global problems. Foreign language education is one of the fields of study which provides appropriate conditions for the integration of global issues as contexts into the learning environment within the framework of Theme-based Approach. The learners thus not only develop their language skills but also use the language to communicate meaningfully within contexts derived from global issues. Moreover, such an approach would help learners to develop an awareness, skills and positive attitudes towards these issues.

As stated before, Global Issues in Language Education (GILE) have sparked interest as a relatively recent approach in the field of ELT, resulting in the rethinking of the main objectives and missions of English teaching (Cates, 1997). However, it seems that foreign language teacher education has so far failed to focus on global perspectives as a way to promote teacher trainees' development as both globally, socially and linguistically competent future teachers. The foreign language teacher education within the context of the current study is no exception and is characterized by lack of foci on global issues. If we, as foreign language teacher educators, are to empower our teacher trainees with the knowledge and skills as globally aware individuals and language teachers, the infusion and integration of global issues into foreign language teacher education programs should be customary and more than lip-service.

As a response to the lack of foci on global issues in foreign language teacher education in Turkey, a new initiative was taken, and as part of a larger research project, an elective GILE-based course was included in the ELT program of a large state university within the framework of Socially Responsible Teaching (SRT). The main incentive for the inclusion of this GILE- based course was to initiate-and substantiate- efforts to integrate global issues into foreign language teacher education and thus to contribute to the linguistic and social development of ELT trainees.

The current research was then undertaken to evaluate the aforementioned GILE-based course, as perceived by ELT teacher trainees and posed the following research questions:

1. What do the ELT trainees expect from a GILE-based course in a foreign teacher education program?

2. Have the ELT trainees' expectations been met after taking the GILE-based course?

It was hoped that the answers to those questions would provide a firm basis for the development of the newlyintroduced GILE-based course and similar other courses in language teacher education programs and would, in turn, help maintain efforts to make future language teachers socially aware and responsible citizens. Also, earlier studies that have aimed to investigate ELT teacher trainees' awareness about and attitudes towards global issues provide support for the integration of global issues into foreign language teacher programs (see Arıkan, 2009; Cates, 1997; Erten, 2004; 
Gürsoy, 2010; Gürsoy, 2012; Gürsoy \& Sağlam, 2011; Jacobs, Goatly, \& Ming, 1995; Karn, 2007; Sağlam \& Gürsoy, 2010). These studies indicate that although ELT teacher trainees have an awareness on environmental issues, as part of GILE, they do not take necessary actions to prevent these problems (Sağlam \& Gürsoy, 2010) and that they have mildly positive attitudes towards environmental education but strong tendency to integrate it into language lessons (Gürsoy \& Sağlam, 2011). Moreover, some studies even argue that environmental education should start as early as pre-school or primary school (Şimşekli, 2004; Erten, 2004) while the children are in the process of developing value judgments and beliefs. Supporting this view several studies argued that environmental issues can be used as a context for child ELT learners as well (Gürsoy, 2010; Gürsoy, 2012).

\section{Methodology}

A quasi-experimental research design was adopted to investigate the trainees' expectations from the course. Data were collected via a questionnaire administered before and after the course was implemented in order to compare the trainees' expectations from and views about the GILE-based course.

\section{Course Description}

As a new initiative in the ELT program the GILE-based course drew on "Theme-based Language Learning" as an approach to improve language skills and aspects of the participants by using environmental problems as a context. The course was offered within the fall term in 2013-2014 academic year, and one of the authors in the current study carried out the lessons. The class met two lesson hours once a week. Throughout the course, videos and a textbook that was developed for the aforementioned larger project were used. The textbook consisted of a variety of language skills and vocabulary activities related to topics on environmental issues, however, due to constraints on class time, not all of the planned classroom activities were completed. This constituted one of the limitations of the study, which was discussed in detail in the conclusion part. The "Home" documentary prepared by Yann Artus- Bertrand was used as the main audiovisual material throughout the course. The documentary basically talks about the diversity of life and focuses on the human threats to the ecology of the Earth. The textbook used contained activities regarding the content of the documentary. Several other documentary films were also used to supplement the main material.

\section{Participants}

All of the fourth-year ELT trainees $(n=28)$ enrolled in the course contributed to the study. Demographic data on the participants revealed that only three out of 28 were a member of an environmental organization and almost half of them $(n=13)$ took the course because it was a better alternative to another elective course offered. 10 of the participants were male, 18 of them female.

\section{Instrument}

The research was carried out in two phases. The first phase aimed to understand ELT teacher trainees' expectations from and views about a language course that used environmental problems as its major and organizing theme. Data were collected via a pre-questionnaire developed by the researchers through an extensive literature review. The questionnaire consisted of two parts. In the first part were open-ended questions that asked the participants to state their views about the possible benefits of a GILE-based course and to talk about their expectations from it. The second part was designed as a five-point Likert-scale and attempted to gain insights into the participants' environmental awareness and expectations from the course. The second phase of the study was carried out at the end of the academic term. The questionnaire used in the first phase of the study was modified and re-administered to reveal ELT trainees' views after the GILE-based course.

The current study yielded both qualitative and quantitative data. In order to analyze the qualitative data, the participants' responses to the open-ended questions in the pre-questionnaires were first read thoroughly by the researchers, and a coding scheme was developed. The qualitative data in the post-questionnaires were analyzed in light of the same coding framework to make a comparison possible between the participants' responses to the pre-and postquestionnaires. All qualitative data were also described in the form of frequencies. As the number of the participants is smaller than 30 ( $N=28$ ), a non-parametric test was used to analyze the data. Thus, in order to compare the participants' 
responses to the pre-and post-questionnaires, the Wilcoxon signed-rank test was used, which is a non-parametric test procedure used to compare two sets of scores that come from the same participants when the use of the dependent ttest is not appropriate (Can, 2014). The means and medians of the participant responses were also calculated.

\section{Findings}

As mentioned earlier, the current study produced both qualitative and quantitative data. In what follows, the findings of the quantitative data are first presented. This is followed by the report of the findings from the qualitative data presented according to each questionnaire item in the pre-and post-questionnaires.

\section{Findings from the Quantitative Data}

The analysis of the quantitative data indicated that there were no statistically significant differences between the pre- and post-questionnaire results $(z=-0.62, p>0.05)$. However, in an item by item comparison statistically significant differences were found in four of the items of the questionnaire (item $1(z=-2.45, p>0.05)$, item $2(z=-3.34, p>0.05)$, item $3(z=$ $3.08, p>0.05)$ and item $4(z=-2.80, p>0.05))$. When the means of these items are analyzed, it can be said that there is a decrease in the post-questionnaire (see Table 1)

Table 1. Comparison of Pre- and Post-test means and modes

\begin{tabular}{llllll}
\hline \multirow{2}{*}{ Mean } & & Item 1 & Item 2 & Item 3 & Item 4 \\
\multirow{3}{*}{ Median } & Pre-test & 3.82 & 3.96 & 3.89 & 3.92 \\
& Post-test & 3.03 & 3.17 & 3.00 & 3.14 \\
& Pre-test & 4.00 & 4.00 & 4.00 & 4.00 \\
\hline
\end{tabular}

\section{Findings from the Qualitative Data}

The qualitative data in the current study consisted of the participants' responses to the open-ended questions in the preand post-questionnaires. In the pre-questionnaire, there were a total of five questions which aimed to gain insights into the ELT trainees' expectations and views of a GILE-based course before it was implemented. The post-questionnaire included 4 questions which attempted to reveal the participants' views after the course was completed.

When asked in the pre-questionnaire what they thought they would be learning in the GILE-based course, the majority of the students stated that the course would develop their 'world knowledge' $(n=17)$ and 'environmental awareness' $(n=16)$. As can be seen in Table 2, these were followed by, in descending order, 'learning how to develop their own students' environmental awareness', 'speaking', 'listening', 'reading', and 'geography.' The two of the participants reported that they did not have an idea about what they would be learning in the course. One of the participants, on the other hand, said that the course would not contribute to his/her development of environmental awareness.

Table 2. ELT trainees' expectations from the GILE-based course before it was implemented

\begin{tabular}{ll}
\hline & $(\mathrm{N}=28)$ \\
\hline 1. I will develop my environmental awareness. & 16 \\
2. It will develop my world knowledge. & 11 \\
3. I will be learning about cultural and natural richness in the world. & 6 \\
4. I will be learning how to raise my own students' environmental awareness. & 4 \\
5. My speaking skills will be developed. & 2 \\
6. My listening skills will be developed. & 2 \\
7. My reading skills will be developed. & 1 \\
8. I will be learning about geography. & 1 \\
9. I don't have an idea. & 2 \\
10. This course will not contribute to the development of my environmental awareness. & 1 \\
\hline &
\end{tabular}


In the post-questionnaire, the participants were asked to state this time what they thought they had learned in the GILEbased course. As shown in Table 3, nearly most of the participants reported that their 'knowledge of vocabulary' $(n=17)$ and 'world knowledge' ( $n=17)$ were developed. These were the responses which ranked the highest of all the others. One of the trainees provided no response.

Table 3 ELT trainees' views about the GILE-based course after it was implemented

\begin{tabular}{ll}
\hline & $(\mathrm{N}=28)$ \\
\hline 1. My knowledge of vocabulary has been developed. & 17 \\
2. My world knowledge has been increased. & 17 \\
3. My environmental awareness has been raised. & 5 \\
4. My knowledge of environment has been refreshed. & 2 \\
5. My speaking skills have been developed. & 1 \\
6. My listening skills have been developed. & 1 \\
7. My reading skills have been developed. & 1 \\
8. I am now more interested in documentaries. & 1 \\
9. I have learned how to integrate environmental issues into language teaching. & 1 \\
10. I haven't developed environmental awareness. & 1 \\
11. I don't have an idea. & 1 \\
\hline
\end{tabular}

Another question in the pre-and post-questionnaires asked the participants to state their views about the integration of environmental issues into foreign language classes and to explain their reasons for their answers. As indicated in Table 4,22 of the participants reported positive ideas about the use of environmental issues in language classrooms. Four of them disagreed with the idea that environmental issues should be part of foreign language classes. Two of the trainees recommended that environmental issues be dealt with in a separate course. There was only one participant who was not able to offer a specific view.

Table 4 ELT trainees' views about the integration of environmental issues into foreign language classes: Prequestionnaire

\begin{tabular}{ll}
\hline & $(\mathrm{N}=28)$ \\
\hline 1. Environmental issues should be within the scope of foreign language classes. & 22 \\
2. Environmental issues shouldn't be within the scope of foreign language classes. & 3 \\
3. Environmental issues should be a separate course. & 2 \\
4. I am undecided. & 1 \\
\hline
\end{tabular}

When asked to explain why environmental issues should be within the scope of foreign language classes, the participants mentioned the following, as indicated in Table 5.

Table 5 ELT trainees' views about why environmental issues should be integrated into foreign language classes: Prequestionnaire

\begin{tabular}{lc}
\hline $\begin{array}{l}\text { Environmental issues should be within the scope of foreign language classes, because this } \\
\text { would... }\end{array}$ & $(\mathrm{N}=28)$ \\
\hline 1. provide the ground for theme-based language instruction. & 9 \\
2. develop environmental awareness. & 8 \\
3. contribute to the development of language skills. & 2 \\
4. offer motivating and interesting content. & 2 \\
\hline
\end{tabular}


5. develop vocabulary knowledge.

6. promote intercultural understanding and communication.

7. facilitate cultural awareness.

In the post-questionnaire data, an increase was observed in the number of the participants who agreed that environmental issues should be infused into foreign language learning and teaching $(n=26)$. Two of the participants did not offer any response (Table 6).

Table 6. ELT trainees' views about the integration of environmental issues into foreign language classes: Postquestionnaire

\begin{tabular}{ll}
\hline & $(\mathrm{N}=28)$ \\
\hline 1. Environmental issues should be within the scope of foreign language classes. & 26 \\
2. No response. & 2 \\
\hline
\end{tabular}

In the post questionnaires, the participants mentioned the following as to their reasons for the integration of environmental issues into foreign language classes (Table 7):

Table 7 ELT trainees' views about why environmental issues should be integrated into foreign language classes: Postquestionnaire

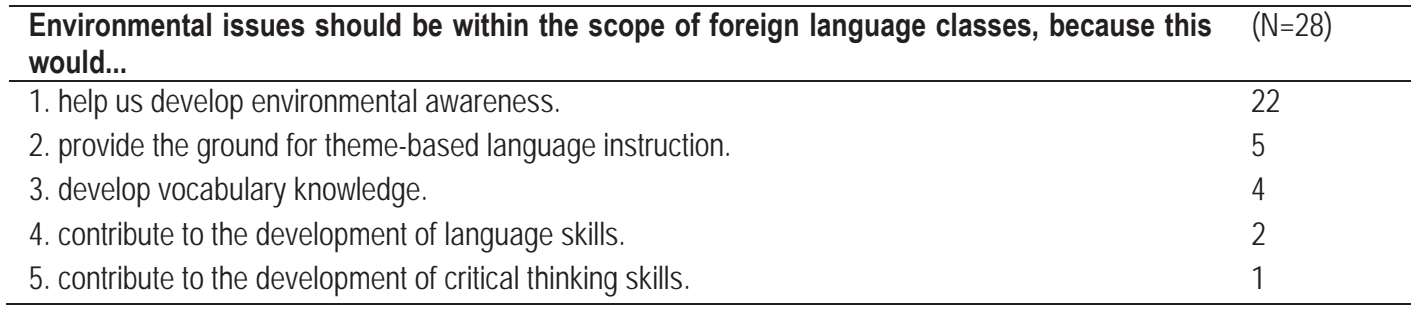

In another question in the pre-questionnaire, the participants were asked to mention their reasons for why they decided to take the GILE-based course. 13 of the participants reported that they took it to shy away from the other elective courses offered at the department. For 11 of them, their incentive for taking the course was to learn about different cultures. The other reasons stated by the participants ranked, in descending order, as in the following (Table 8):

Table 8. ELT trainees' reasons for taking the GILE-based course: Pre-questionnaire

\begin{tabular}{lc}
\hline & $(\mathrm{N}=28)$ \\
\hline 1. I don't want to take 'Pragmatics'. & 13 \\
2. I would like to learn more about different cultures. & 11 \\
3. It looks like an interesting lesson. & 10 \\
4. It is a new elective course offered in the department. & 9 \\
5. It looks like easy to pass. & 7 \\
6. I am interested in global issues. & 4 \\
7. I'd like to develop my speaking skills. & 3 \\
8. It is similar to Geography. & 3 \\
9. I'd like to develop my environmental awareness. & 2 \\
10. It will be an audio-visual course. & 1 \\
11. It will involve different types of materials. & 1 \\
12. I liked the content of the lesson. & 1 \\
13. I'd like to make others aware of environmental issues. & 1 \\
\hline
\end{tabular}


14. My friends have just taken it.

15. I like animals.

\section{1}

1

In the post-questionnaire, the trainees were asked to state if their reasons for taking the GILE-based course matched with the course content and activities. As shown in Table 9, most of the trainees articulated that the course met their initial expectations to a large or some extent and that the course content and activities matched with their reasons for taking it. Seven of them, on the other hand, reported the reverse. Four of the participants did not provide any response.

Table 9 ELT trainees' views about if the course met their initial expectations: Post-questionnaire

\begin{tabular}{ll}
\hline & $(\mathrm{N}=28)$ \\
\hline 1. To a large extent. & 10 \\
2. To some extent. & 7 \\
3. It did not meet my expectations. & 7 \\
4. No response. & 4 \\
\hline
\end{tabular}

In the post-questionnaires, the participants also expressed their ideas about why the course content and their expectations matched or did not match with each other. Some of the trainees who reported that there was not a mismatch between the course itself and their initial expectations mentioned the following (Table 10):

Table 10. ELT trainees' views about the match between their initial course expectations and the course content: Postquestionnaire

\begin{tabular}{ll}
\hline To large/some extent the course has met my initial expectations, because... & $(\mathrm{N}=28)$ \\
\hline 1. I will be able to develop my students' environmental awareness. & 1 \\
2. I developed my own English. & 1 \\
3. My speaking skills were developed. & 1 \\
4. My reading skills were developed. & 1 \\
5. I developed my vocabulary knowledge. & 1 \\
\hline
\end{tabular}

The trainees who reported a mismatch between their own initial course expectations and the course itself expressed the following as their concerns (Table 11):

Table 11 ELT trainee views' about the mismatch between their initial course expectations and the course content: Postquestionnaire

\begin{tabular}{ll}
\hline The course hasn't met my initial expectations, because... & $(\mathrm{N}=28)$ \\
\hline 1. We could have watched more videos. & 6 \\
2. A variety of topics could have been used. & 4 \\
3. There was overemphasis on reading. & 4 \\
4. There was overemphasis on vocabulary. & 4 \\
5. There should have been more speaking activities. & 3 \\
6. We could have joined environmental protection activities. & 2 \\
7. There was little emphasis on the development of world knowledge. & 1 \\
8. There should have been more listening activities. & 1 \\
9. There wasn't a focus on how to teach environmental awareness. & 1 \\
10. There was an overemphasis on environment. & 1 \\
11. There should have been a variety of activities. & 1 \\
12. There was an overemphasis on language, not on a theme. & 1 \\
13. Geography could have been one of the themes to study. & 1 \\
\hline
\end{tabular}


The other question included both in the pre-and post-questionnaires was concerned with the ELT trainees' views about the possible contributions of the GILE-based course to their own development as future language teachers. In the prequestionnaires, nearly all of the participants $(n=27)$ agreed that the course would contribute to their own development.

Table 11a. ELT trainees' views about the contributions of the GILE-based course: Pre-questionnaire

\begin{tabular}{ll}
\hline & $(\mathrm{N}=28)$ \\
\hline 1. The course will contribute to my development. & 27 \\
2. The course will not contribute to my development. & 1 \\
\hline
\end{tabular}

When asked to explain in what ways it might foster their development, the participants mentioned the following, in descending order:

Table 11b.ELT trainees' views about the contributions of the GILE-based course: Pre-questionnaire

\begin{tabular}{ll}
\hline & $(\mathrm{N}=28)$ \\
\hline 1. It will develop my world knowledge. & 14 \\
2. It will help me develop my own students' environmental awareness. & 8 \\
3. It will develop my own environmental awareness as a prospective teacher. & 5 \\
4. It will develop my knowledge of environment-related vocabulary. & 5 \\
5. It will develop my speaking skills. & 4 \\
6. It will contribute to my language development. & 3 \\
7. It will help me integrate environmental issues into language education. & 2 \\
8. It will develop my listening skills. & 2 \\
9. It will develop my writing skills. & 1 \\
10. It will develop my reading skills. & 1 \\
11. It will develop my pronunciation. & 1 \\
12. It will develop my critical thinking skills. & 1 \\
13. It will encourage me for being a member of environmental organizations. & 1 \\
\hline
\end{tabular}

In the post-questionnaires, the participants were asked to respond to the same question about the possible contributions of the GILE-based course. Most of the trainees $(n=26)$ stated that the course positively contributed to their personal and professional development.

Table 12. ELT trainees' views about the contributions of the GILE-based course: Post-questionnaire

\begin{tabular}{ll}
\hline & $(\mathrm{N}=28)$ \\
\hline 1. I have developed my vocabulary knowledge. & 14 \\
2. I have learned how to develop my students' environmental awareness. & 8 \\
3. I have developed my reading skills. & 3 \\
4. I have developed my world knowledge. & 3 \\
5. I have developed environmental awareness. & 2 \\
6. I have an idea now about topic/themes to use in my own classes. & 2 \\
7. I have developed my speaking skills. & 1 \\
8. I have developed my pronunciation. & 1 \\
9. It will help me in KPSS. & 1 \\
10. I can use the textbook we have used in this course. & 1 \\
11. I have developed my language awareness. & 1 \\
\hline
\end{tabular}


According to half of the trainees $(n=14)$, the course greatly contributed to the development of their vocabulary knowledge. This was followed by the development of environmental awareness $(n=8)$.

Table 12a ELT trainees' views about the contributions of the GILE-based course: Post-questionnaire

1. The course has contributed to my development.

2. The course hasn't contributed to my development.

\section{Discussion}

The findings from the quantitative data indicated that in the overall comparison of the pre- and post-questionnaires, there were no statistically significant differences. Thus, it can be argued that the participants' initial expectations from the GILEbased course were met at the end of the course. However, a more detailed analysis of the findings showed that there were statistically significant differences between four of the questionnaire items, which indicates a change in the participants' views. In Item 1, the teacher trainees stated that the course would play an important role in developing their awareness on environment and environmental protection. Although, in both questionnaires, the means indicated that the trainees agreed with this item, the number of the participants who agreed with it was decreased. This decrease was also apparent in the qualitative data. The analysis revealed that the number of participants who stated that the course contributed to their environmental awareness was decreased. In addition, in the open-ended questionnaires, the majority of the trainees indicated that the course content would help them develop their world knowledge. This expectation seems to be met as there was not any change in the number of the participants who reported that the course would contribute to the development of their world knowledge before and after the course was implemented. Interestingly, at the beginning of the course, none of the trainees mentioned the development of their vocabulary knowledge as one of the possible contributions of the course, yet at the end of the course the majority thought that their vocabulary knowledge expanded.

In both questionnaires, the trainees agreed that the course would help them with the ways to develop environmental awareness in language lessons. Yet, again the number of the trainees who agreed with the item decreased in the post questionnaire. The trainees also thought that the course would show them the ways to raise their own students' environmental awareness. By the end of the course, fewer trainees agreed with the issue. According to the qualitative findings, the majority of the participants think that environmental issues should be within the scope of foreign language lessons. In the post-questionnaire there was an increase in the number of trainees who thought so. To support their ideas, they mentioned that this would create opportunities for theme -based teaching and help develop environmental awareness of their prospective students. This result is promising in that it is an indication of ELT teacher trainees' awareness of the benefits of contextualized language learning as well as of the significance of using environmental topics for teaching a foreign language. However, quantitative results suggested that the trainees needed specific instruction to implement environmental education in their classes as they were not satisfied with the fact that the GILE-based course does not cover methodological aspects.

Finally, according to the quantitative data, in the pre-questionnaire, more trainees expected that the course would help them develop their social responsibility, whereas, in the post-questionnaire this expectation was met according to fewer participants. It is interesting that only these four items are related to their self and future career as the items were mostly concerned with the integration of environmental awareness into ELT and the development of environmental awareness. The rest of the items inquired the contribution of the course to the participants' language skills development and the content of the course.

According to the responses given in the open-ended part of the questionnaire, almost all of the participants agreed that the course contributed to their personal and professional development. However, some of the areas of development were different from what they expected at the beginning of the course. When they started the course, half of the participants thought that the course would help them develop their world knowledge, yet only three of them agreed that this was achieved by the end of the course. The number of participants who thought that the course would help them develop their prospective students' awareness did not change in each questionnaire. However, although, at the beginning of the term, the majority did not expect that their vocabulary knowledge would expand, half of the participants 
claimed that the course helped them develop their vocabulary knowledge by the end of the course. A few trainees also had some expectations regarding the development of their speaking skill, but this expectation seemed not to be met.

These results indicate that the trainees hold positive views about the integration of global issues (especially environmental issues) into their own education as a tool for both personal and professional development. As the content of the course was not designed as a methodology course to teach methods and techniques to integrate environmental issues into the ELT curriculum, the change in some of the trainees' expectations seems to be reasonable. On the other hand, the difference in the participants' expectations regarding the contribution of the course to the development of their environmental awareness can be a result of the course materials. As the major video and text material used in the course was the "Home" documentary, the content and discussions centered on the topics presented in these materials. However, the responses to the open-ended part of the questionnaire pointed to the participants' preference for a variety of topics, along with the ones included in the course.

Another finding worth mentioning in the quantitative data was related to the trainees' reasons for selecting the course. According to what most of the participants reported in the quantitative part of the questionnaire, they decided to take this course only because it fit their schedule. This finding itself seems to be an important indicator of the participants' lack of awareness when selecting a GILE-based course. It can thus be inferred from this finding that the participants' main concern was not to develop their language skills and environmental awareness. The fact that the responses remained the same in the post-questionnaire is also important to understand the participants' incentive to be enrolled in the course. The qualitative data also support all these findings. Almost half of the trainees reported that they took the course because they did not want to take the other elective courses which they thought might be difficult to succeed in. Some others also mentioned that they took the course because it was a new course offered at the department and it seemed interesting. It might thus be argued that the trainees did not make informed and conscious decisions for taking the GILE-based course. This might be explained on the trainees' lack of knowledge of the course and the course content, because it was a new course offered at the department.

In the post-questionnaires, the participants also stated that they were expecting a variety of topics and video materials to be used in the classes rather than a focus on a single documentary. A few participants complained about the over- emphasis on reading and vocabulary, and some mentioned that they expected to do more speaking activities. Such mismatches between the course content and the trainees' expectations are valuable in re-designing the course for the following academic year.

\section{Concluding remarks}

The findings from the research are valuable in that they provide insights for course designers. It seems that although the participants did not have sound reasons to take the course at the beginning of the term, it helped them develop professionally by creating an awareness regarding the integration of global issues into the ELT curriculum and by helping develop their linguistic skills. Their feedback on the course content such as the use of a variety of topics and materials and more emphasis on the development of speaking skill are of importance when selecting the materials and activities for the future implementation of the GILE-based course.

Although the small number of participants and the constraints on time in the implementation of the course do not allow us to make claims as to the generalizability of the results, the current study also seems to indicate that the integration of global issues into the foreign language teacher education programs within SRT might aid in the development of ELT trainees' environmental awareness and linguistic skills. This information could therefore be a genesis of act for taking similar initiatives to develop GILE-based courses at foreign language teacher education programs.

\section{References}

Arıkan, A. (2009). Environmental peace education in foreign language learners' English grammar lessons. Journal of Peace Education, 6(1), 87-99.

Can, A. (2014). SPSS ile bilimsel araştırma sürecinde nicel veri analizi. Ankara: Pegem Akademi.

Cates, K. A. (1990). Teaching for a better world: Global issues and language education. The Language Teacher, 41-52.

Cates, K. A. (1997). New trends in global issues and English teaching. The Language Teacher Online, 21(05).

Retrieved from: http://jalt-publications.org/old tt/files/97/may/cates.html

Erten, S (2004). Çevre eğitimi ve çevre bilinci nedir, çevre eğitimi nasıl olmalıdır? [What is environmental education and environmental awareness, how should environmental education be done?] Çevre ve Insan Dergisi, 65. 
Fisher, S. \& Hicks, D. (1985). World Studies 8-13. New York: Oliver \& Boyd.

Freire, P. (2005). Pedagogy of the oppressed (30th Anniversary Ed.). New York: Continuum.

Gürsoy, E. (2010). Theme-based teaching: Environmental education. In E. Gürsoy \& A. Arıkan (Eds). Teaching English to young learners: An activity-based guide for prospective teachers. Ankara: Eğiten Kitap.

Gürsoy, E. (2010). Implementing environmental education to foreign language teaching to young learners. Educational Research, 1(8), 232-238.

Gürsoy, E. \& Sağlam, G. T. (2011). ELT teacher trainees' attitudes towards environmental education and their tendency to use it in the language classroom. Journal of International Education Research - JIER, 7(4), 47-52.

Hicks, D. \& Bord, A. (2001). Learning about Global Issues: Why most educators only make things worse. Environmental Education Research, 7(4), 413-425.

Jacobs, G. M., Goatly, A., and Ming, J. (1995). Language and the environment. PASAA, 25, 54-63.

Karn, S. K. (2007). Current trends in ELT around the globe. Journal of NELTA, 12, (1\&2), 60-66.

Kniep, W. (1985). A Critical Review of the Short History of Global Education. New York: American Forum for Global Education.

Peaty, D. (2004). Global issues in EFL: Education or indoctrination? The Language Teacher, 28(8), 15-18.

Sağlam, G.T. \& Gürsoy, E. (2010). ELT teacher trainees' awareness on environmental issues and their integration to the curriculum. Proceedings from ICONTE-International Conference on New Trends in Education and Their Implications, 11-13 Nov., 2010, Antalya, Turkey.

Shor, I. \& Freire, P. (1987). A pedagogy for liberation. South Hadley, MA: Bergin and Garvey.

Şimşekli, Y. (2004). Çevre bilincinin gelişmesine yönelik çevre eğitimi etkinliklerine ilköğretim okullarının duyarlıı̆ı. Uludag University Journal of the Faculty of Education, 17(1), 83-92.

Yahoo News (23 March, 2014). UN scientists see grim future if no climate action. Retrieved from http://news.yahoo.com/un-scientistssee-grim-future-no-action-035340842.html 